\title{
Type 2 Superior Labral Anterior to Posterior Lesion-Related Paralabral Cyst Causing Isolated Infraspinatus Paralysis: Two Case Reports
}

\author{
Yong Ki Lee, $\mathrm{MD}^{1}$, Eun Young Han, $\mathrm{MD}^{1}$, Sung Wook Choi, MD, $\mathrm{PhD}^{2}$, Bo Ryun Kim, MD, $\mathrm{PhD}^{1}$, Min Ji Suh, MD
}

\begin{abstract}
Departments of ${ }^{1}$ Rehabilitation Medicine and ${ }^{2}$ Orthopaedic Medicine, Jeju National University Hospital,
\end{abstract} Jeju National University School of Medicine, Jeju, Korea

Type 2 superior labral anterior to posterior (SLAP) lesion is a common cause of shoulder pain requiring surgical operation. SLAP tears are often associated with paralabral cysts, but they rarely cause nerve compression. However, we experienced two cases of type 2 SLAP-related paralabral cysts at the spinoglenoid notch which were confirmed as isolated nerve entrapment of the infraspinatus branch of the suprascapular nerve by electrodiagnostic assessment and magnetic resonance imaging. In these pathological conditions, comprehensive electrodiagnostic evaluation is warranted for confirmation of neuropathy, while surgical decompression of the paralabral cyst combined with SLAP repair is recommended.

Keywords Shoulder pain, Electromyography, Ganglion cysts, Nerve compression syndromes

\section{INTRODUCTION}

Superior labral anterior to posterior (SLAP) lesions are a common cause of shoulder pain with an incidence of $3.9 \%-11.8 \%$ in the general population, and are usually associated with other shoulder problems such as rotator cuff tears, instability, or other biceps tendon pathologies [1]. Among the various types of SLAP lesions, type 2 lesions are the most common subtype accounting for $41 \%$ of lesions [2]. They are characterized by fraying and

Received March 4, 2015; Accepted June 2, 2015

Corresponding author: Eun Young Han

Department of Rehabilitation Medicine, Jeju National University Hospital, 15 Aran 13-gil, Jeju 63241, Korea

Tel: +82-64-717-1672, Fax: +82-64-717-1131, E-mail: clearblue10@naver.com

(ㄷ) This is an open-access article distributed under the terms of the Creative Commons Attribution Non-Commercial License (http://creativecommons. org/licenses/by-nc/4.0) which permits unrestricted noncommercial use, distribution, and reproduction in any medium, provided the original work is properly cited.

Copyright $\odot 2015$ by Korean Academy of Rehabilitation Medicine degeneration of the free edge of the superior labrum with detachment of the biceps anchor from the superior glenoid tubercle, which leads to displacement of the bicepssuperior labrum complex into the glenohumeral joint [2].

Paralabral cysts are rare cause of entrapment of the infraspinatus branch of the suprascapular nerve, although they are commonly related to the SLAP lesion. We report two cases of type 2 SLAP-related paralabral cysts causing isolated neuropathy of the infraspinatus branch of the suprascapular nerve which were confirmed by electromyography (EMG).

\section{CASE REPORTS}

\section{Patient 1}

We report a case of a 62-year-old man who presented with a 3-month history of right posterior shoulder pain. Three months ago, he lifted a heavy object and right shoulder pain appeared abruptly. He was managed con- 
servatively for right shoulder pain with non-steroidal anti-inflammatory drugs, physiotherapy, and rest at local clinics, but all of these techniques provided no benefits. After then, he visited our department.

Physical examination showed painful arc limited to $160^{\circ}$ of right shoulder active abduction and flexion. Posterior shoulder pain was aggravated by external rotation of the right shoulder, but there was no limitation in passive range of motion. There were no abnormal findings on manual muscle tests (MMT) of shoulder muscles.

Neer test, Hawkins impingement test, and empty can test were positive for the right shoulder and plain radiographs were unremarkable. EMG study was performed to exclude cervical radiculopathy, brachial plexus injury, or combined lesions.

Peripheral sensory nerve conduction studies revealed normal findings in the right median, ulnar and lateral antebrachial nerves. Motor nerve conduction studies showed normal findings in the right median, ulnar, axillary and suprascapular nerves. EMG was performed in the right biceps, deltoid, supraspinatus, infraspinatus, flexor carpi radialis, flexor carpi ulnaris, extensor carpi radialis longus, extensor digitorum communis, first dorsal interossei, abductor pollicis brevis, and C5, C6, C7 paraspinalis. Only the infraspinatus demonstrated fibrillations and positive sharp waves at rest and both normal and polyphasic motor unit potentials with minimally reduced recruitment on volition.

Magnetic resonance imaging (MRI) scans of the right shoulder revealed a type 2 SLAP lesion with a large paralabral cyst (Fig. 1) extending to the suprascapular and spinoglenoid notches, and fatty atrophy of the infraspina- tus muscle. A partial tear of the supraspinatus and biceps tendinosis were also observed. The patient was referred to the department of orthopaedic surgery of our hospital. The surgeon recommended surgical decompression and SLAP repair, but he refused and follow-up data cannot be available.

\section{Patient 2}

We report another case of a 56 -year-old male who presented with a 1-month history of right shoulder pain. $\mathrm{He}$ visited the department of orthopedic surgery and was managed conservatively for right shoulder pain with non-steroidal anti-inflammatory drugs, physiotherapy, rest, and local injections of corticosteroids which provided only minimal benefits. Physical examination showed tenderness and pain in the right posterior shoulder and greater tuberosity, and it also revealed atrophy of the infraspinatus muscle. All of the examined shoulder muscles except for the external rotators showed normal strength in the MMT and there was no limitation in passive range of motion.

However, he complained of severe pain (visual analog scale [VAS], 8) while controlling the steering wheel, and Neer test, Hawkins impingement test, O'Brien's test, and Speed's test were positive for the right shoulder. Plain radiographs were unremarkable and he was referred to our EMG laboratory for evaluation of the peripheral nerve lesion.

Sensory nerve conduction studies showed normal findings in all of the examined nerves (Table 1), but motor nerve conduction studies revealed low amplitude responses to right suprascapular nerve stimulation on infraspinatus muscle recordings (Table 2). Needle EMG of


Fig. 1. (A) Coronal oblique T2weighted magnetic resonance imaging shows paralabral cyst (arrow) extending to the suprascapular notch. (B) Sagittal oblique T2-weighted magnetic resonance imaging shows fatty atrophy of the infraspinatus muscle (I), compressed by a paralabral cyst (arrow). D, deltoid; Sub, subscapularis; S, supraspinatus; T, teres minor. 
Table 1. Sensory nerve conduction studies

\begin{tabular}{|c|c|c|c|c|}
\hline \multirow{2}{*}{ Nerve (stimulation-recording site) } & \multicolumn{2}{|c|}{ Right side } & \multicolumn{2}{|c|}{ Left side } \\
\hline & Latency (ms) & Amplitude $(\boldsymbol{\mu V})$ & Latency (ms) & Amplitude $(\boldsymbol{\mu V})$ \\
\hline Superficial radial (wrist-thumb) & 2.45 & 39.3 & 2.2 & 39.8 \\
\hline $\begin{array}{l}\text { Lateral antebrachial cutaneous nerve } \\
\text { (elbow-forearm) }\end{array}$ & 2.35 & 33.7 & 2.3 & 43.2 \\
\hline Median (wrist-III digit) & 3.6 & 22.4 & - & - \\
\hline Ulnar (wrist-V digit) & 3.5 & 17.5 & - & - \\
\hline
\end{tabular}

Table 2. Motor nerve conduction studies

\begin{tabular}{|c|c|c|c|c|}
\hline \multirow{2}{*}{ Nerve (stimulation-recording site) } & \multicolumn{2}{|c|}{ Right side } & \multicolumn{2}{|c|}{ Left side } \\
\hline & Latency (ms) & Amplitude (mV) & Latency (ms) & Amplitude (mV) \\
\hline Suprascapular (Erb's point-supraspinatus) & 1.85 & 8.3 & 1.95 & 8.2 \\
\hline Radial (wrist-EIP) & 1.95 & 7.7 & 1.60 & 7.4 \\
\hline Musculocutaneous (Erb's point-biceps) & 3.90 & 12.2 & 3.85 & 12.9 \\
\hline Median (wrist-APB) & 3.85 & 8.1 & - & - \\
\hline Ulnar (wrist-ADQ) & 2.55 & 8.8 & - & - \\
\hline
\end{tabular}

EIP, extensor indicis proprius; APB, abductor pollicis brevis; $A D Q$, abductor digiti quinti.

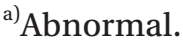
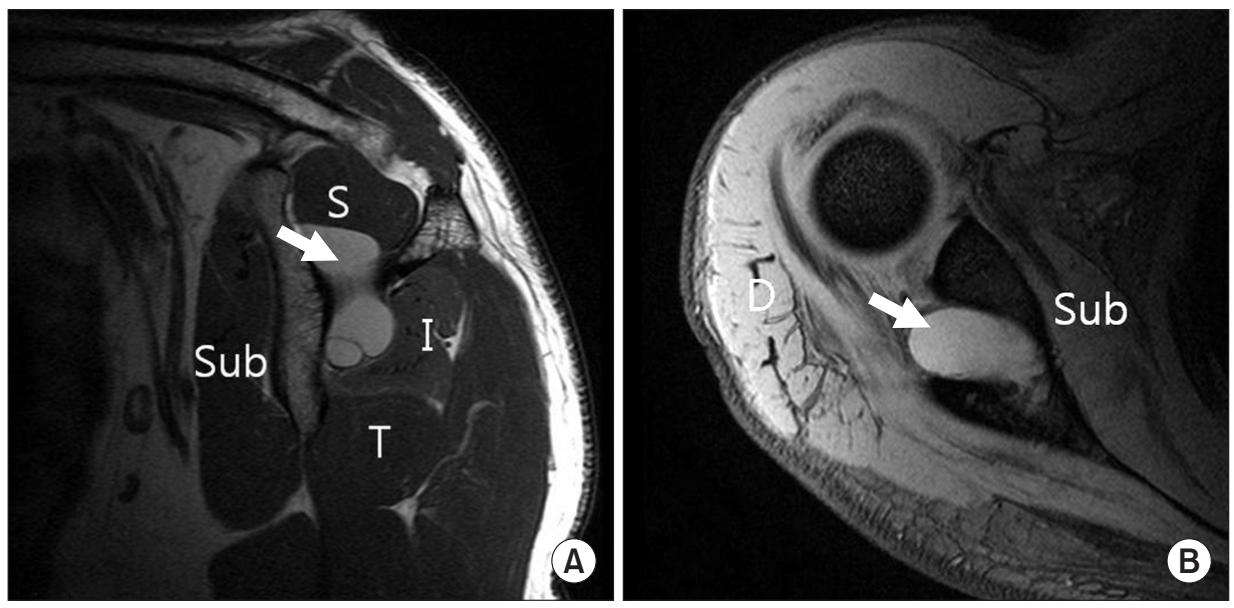

Fig. 2. (A) Sagittal oblique T2weighted magnetic resonance imaging shows paralabral cyst (arrow) at the suprascapular notch and slightly high signal intensity of the infraspinatus muscle (I). (B) Axial T2-weighted magnetic resonance imaging reveals paralabral cyst (arrow). D, deltoid; Sub, subscapularis; S, supraspinatus; T, teres minor.

the right infraspinatus muscle demonstrated fibrillations and positive sharp waves at rest and polyphasic motor unit potentials with reduced recruitment on volition.

MRI scans of the right shoulder revealed a posterior type 2 SLAP lesion with an approximately $2.6 \times 2.6 \times 3.2 \mathrm{~cm}$ sized paralabral cyst and biceps tendinosis (Fig. 2).

We recommended paralabral cyst decompression and SLAP repair and the patient underwent arthroscopic management. The labral tear due to the SLAP lesion was repaired with suture anchors and the paralabral cyst at the spinoglenoid fossa was decompressed, and shoulder abduction brace was applied.

Since the 7th post-operative (post-op) day, he received continuous passive motion therapy, and on the 14th postop day, the surgical wound was stitched and isometric exercise for shoulder external rotators was prescribed. Six weeks after surgery, the abduction brace was removed and his pain score (VAS) was reduced to 3 . Active- 
assisted stretching and strengthening exercise and physical modality for reducing the pain were prescribed and they were maintained until 3 months after operation. At 12 months postoperatively, the shoulder pain score decreased to zero and the strength of his shoulder external rotators improved to a good grade in the MMT. Amplitude of the right suprascapular nerve on infraspinatus muscle recordings was improved to the normal range (right 5.2 $\mathrm{mV}$, left $7.0 \mathrm{mV}$ ) and needle EMG of the right infraspinatus muscle demonstrated increased insertional activity at rest and large amplitude normal and polyphasic motor unit potentials with full recruitment on volition.

\section{DISCUSSION}

We report two cases of type 2 SLAP-related paralabral cysts at the spinoglenoid notch causing isolated entrapment of the infraspinatus branch of the suprascapular nerve. Paralabral cysts are thought to arise from synovial fluid leakage through a weakened site of the joint capsule. Several studies indicate that ganglion cysts of the spinoglenoid notch, which result from repetitive overhead activity, involve a one-way valve mechanism that is related to labral tears [3]. Paralabral cysts are commonly observed in the spinoglenoid notch, but they rarely cause suprascapular neuropathy which induces shoulder muscle weakness and pain [4].

The suprascapular nerve is a mixed peripheral nerve arising from the upper trunk of the brachial plexus, which is usually formed by the roots of $\mathrm{C} 5$ and $\mathrm{C} 6$ at Erb's point, then running posterior to the plexus and deep to the trapezius. It then traverses the suprascapular notch on encountering the scapula, innervates the supraspinatus muscle, turns around the lateral edge of the scapular spine to pass through the spinoglenoid notch, and enters the infraspinatus fossa, where it acts as a pure motor nerve to the infraspinatus muscle and provides a sensory branch to the posterior aspect of the glenohumeral joint capsule [5]. Formation of a paralabral cyst in the spinoglenoid notch can result in impairment of the infraspinatus branch of the suprascapular nerve, secondary to a mass effect, with resulting isolated infraspinatus weakness. The exact mechanism behind paralabral cyst formation remains unclear, but there exists a very strong correlation between cysts and labral tears. Tirman et al. [6] reported that labral tears were associated with glenoid labral cysts in all of their patients, and this finding is consistent with a previous study, which reported that $89 \%$ of MRIdocumented ganglion cysts correlated with a labral tear [7].

Treatment options for symptomatic spinoglenoid cysts range from observation to arthroscopic decompression with or without labral repair. Recently, several authors have suggested that these patients can be treated with an isolated SLAP repair because of the large percentage of spontaneous cyst resolution and high satisfaction rates after repair alone [8]. However, Pillai et al. [9] showed that cyst decompression with SLAP repair increased the strength of the external rotators of the shoulder to a greater degree than SLAP repair alone. Although they did not perform EMG evaluation, the strength of the infraspinatus muscle in the subjects could be weakened by suprascapular neuropathy due to SLAP-related cysts and cyst decompression to restore the strength of external rotators.

Recently developed MRI techniques can increase the detection of ganglion cysts or pathological lesions around the shoulder. However, MRI only identifies structural abnormalities and cannot provide confirmation of neuropathy or the severity of denervation or regeneration.

To the best of our knowledge, there are a few case reports in Korea, demonstrating isolated neuropathy of the infraspinatus branch of the suprascapular nerve which resulted from SLAP-related paralabral cysts at the spinoglenoid fossa and was confirmed by electrodiagnostic examination as well as MRI. In addition, we confirmed the regeneration of the infraspinatus by EMG after arthroscopic decompression and serially prescribed physical therapy. These findings provide objective evidence for surgical decompression of paralabral cysts and may guide treatment selection among various options.

In summary, SLAP-related paralabral cysts, although uncommon, can result in compression of the infraspinatus branch of the suprascapular nerve and should be considered in the differential diagnosis of shoulder pain and weakness. Therefore, comprehensive EMG evaluation of the shoulder, including the suprascapular nerve, as well as MRI is recommended for SLAP-related paralabral cysts.

\section{CONFLICT OF INTEREST}

No potential conflict of interest relevant to this article was reported. 


\section{ACKNOWLEGMENTS}

This research was supported by the 2015 scientific promotion program funded by Jeju National University.

\section{REFERENCES}

1. Bencardino JT, Beltran J, Rosenberg ZS, Rokito A, Schmahmann S, Mota J, et al. Superior labrum anterior-posterior lesions: diagnosis with MR arthrography of the shoulder. Radiology 2000;214:267-71.

2. Knesek M, Skendzel JG, Dines JS, Altchek DW, Allen AA, Bedi A. Diagnosis and management of superior labral anterior posterior tears in throwing athletes. Am J Sports Med 2013;41:444-60.

3. Chen AL, Ong BC, Rose DJ. Arthroscopic management of spinoglenoid cysts associated with SLAP lesions and suprascapular neuropathy. Arthroscopy 2003;19:E15-21.

4. Cummins CA, Messer TM, Nuber GW. Suprascapular nerve entrapment. J Bone Joint Surg Am 2000;82:415-24.
5. Fehrman DA, Orwin JF, Jennings RM. Suprascapular nerve entrapment by ganglion cysts: a report of six cases with arthroscopic findings and review of the literature. Arthroscopy 1995;11:727-34.

6. Tirman PF, Feller JF, Janzen DL, Peterfy CG, Bergman AG. Association of glenoid labral cysts with labral tears and glenohumeral instability: radiologic findings and clinical significance. Radiology 1994;190:653-8.

7. Piatt BE, Hawkins RJ, Fritz RC, Ho CP, Wolf E, Schickendantz M. Clinical evaluation and treatment of spinoglenoid notch ganglion cysts. J Shoulder Elbow Surg 2002;11:600-4.

8. Kim DS, Park HK, Park JH, Yoon WS. Ganglion cyst of the spinoglenoid notch: comparison between SLAP repair alone and SLAP repair with cyst decompression. J Shoulder Elbow Surg 2012;21:1456-63.

9. Pillai G, Baynes JR, Gladstone J, Flatow EL. Greater strength increase with cyst decompression and SLAP repair than SLAP repair alone. Clin Orthop Relat Res 2011;469:1056-60. 